\title{
Stop-Motion: Estrategia de Imagen y Comunicación para la mejora de la convivencia
}

\section{Stop-Motion: Image and Communication Strategy for the improvement of coexistence}

\author{
Ana Belén Fernández-del Río, Alberto José Barreira-Arias \\ Universidad de Vigo, España
}

\begin{abstract}
Resumen
El presente estudio muestra los resultados de una experiencia implementada en un grupo-clase de Educación Primaria utilizando el stop-motion como estrategia innovadora basada en la animación y creación audiovisual, para la mejora de la convivencia. En el análisis cualitativo de los datos se utilizó el software ATLAS.ti. Tras la intervención se constata una mejora relevante en el comportamiento de los estudiantes; así como un incremento en su motivación, destacando la adquisición y desarrollo de habilidades como el trabajo colaborativo en donde se aprenden estrategias para resolver problemas. Asimismo, habilidades interpersonales como la comunicación, el liderazgo y la capacidad de decisión.
\end{abstract}

Palabras clave: enfoque basado en competencias, producción de un cortometraje, mejora de la convivencia, innovación

\begin{abstract}
The present study shows the results of an implemented a group-class primary school using the stop-motion as an innovative strategy based animation and audiovisual creation, for improving the living experience. ATLAS.ti software was used in the qualitative analysis of the data. After the intervention a significant improvement is observed in the behavior of students; and an increase in motivation, emphasizing the acquisition and development of skills such as collaborative work where problem solving strategies are learned. Also, interpersonal skills such as communication, leadership and decision-making capacity.
\end{abstract}

Keywords: competency-based approach, production of a short film, improving coexistence, innovation

\section{Introducción}

La presente comunicación muestra un estudio de un grupo-clase de Educación Primaria con graves problemas de convivencia en el ámbito educativo. El objetivo principal es doble: por un lado, se pretende analizar cómo es la progresión de dichos estudiantes y; por otro, ejemplificar este análisis con el uso de una técnica denominada stop-motion enmarcada dentro de la formación en competencia digital, que se ha seleccionado desde la tutoría. Con ella se pretende promover la reflexión educativa de las TIC como instrumento favorecedor de la convivencia de estos estudiantes a través del trabajo colaborativo promoviendo el cambio, la innovación y la mejora.
En la actualidad existen diversas dificultades en la convivencia que dificultan las relaciones armónicas. Para combatir y resolver los conflictos destructivos, las instituciones educativas deben de admitir que estos existen y que algunos de ellos están fuera de control. Por ello, la prevención se fundamenta en una acción educativa y de intervención dirigida a la mejora de la convivencia. Para un proceso de enseñanza-aprendizaje eficaz, además de la formación continua por parte de los profesionales se hace preciso una sensibilización y colaboración de las familias.

Como señala Jares (2001, p. 46) muchas veces se crean conflictos por malos entendidos, por una comunicación inadecuada o por problemas de percepción, debido a que los significados personales no coinciden con la realidad exterior. Es necesario, desde el punto de vista del análisis, hacer la distinción entre conflicto y falso conflicto.

Teniendo en cuenta la naturaleza conflictiva debemos sacar provecho a esta situación ya que las causas son diversas y las responsabilidades múltiples. Para ello, enseñaremos a convivir, analizaremos y presentaremos los conflictos constructivamente, respetando las normas y fomentando los valores a través de actividades colaborativas. Ya que estos tienen más posibilidades de aparecer en un clima donde las normas sean arbitrarias, elaboradas al margen del alumnado, divergentes y poco claras sin que los implicados en su cumplimiento identifiquen cuando estas son de obligado cumplimiento y cuando no.

Pensamos que los problemas de convivencia se pueden reducir si toda la comunidad educativa trabaja de manera conjunta para solventarlo. A través de un análisis DAFO indagamos en las causas que nos han llevado a este deterioro de la convivencia, para poder hacerle frente educativamente, dándole un seguimiento y valorando su eficacia. Después del análisis de la información recogida, se diseñó y aplicó una propuesta educativa haciendo uso de una herramienta didáctico-pedagógica basada en las Nuevas Tecnologías para prevenir y tratar educativamente el conflicto. Posteriormente se evaluó y se presentaron los resultados.

\section{La conflictividad en la institución educativa}

En los centros educativos conviven diariamente diversidad de personas, lo que hace que la naturaleza de este espacio sea conflictivo. La conflictividad no se debe considerar como un obstáculo sino como algo positivo si se trata adecuadamente. La adaptación a la escuela y a la sociedad depende en gran parte de la coordinación entre la familia y la escuela. El profesorado tiene que tratar de lograr una interacción positiva con las familias y contar con su participación y apoyo para facilitar el proceso de integración de los estudiantes.

Como señala Vega-Hazas (2009, p. 165) Encubrir, justificar o culpar a los demás de las faltas de 
los niños/as fomenta irresponsabilidad y actitudes inadecuadas por tener siempre el apoyo de su familia. Las conductas antisociales, los problemas de aprendizaje o la falta de adaptación pueden concluir en fracaso escolar. El profesorado debe respetar y adaptarse a las necesidades de sus estudiantes, valorando no solo los aspectos cognitivos sino también los afectivo-sociales facilitando su integración al grupo.

Como indica Ferrero (2007), la convivencia es el reflejo de una realidad diversa, en la que interaccionamos con personas con intereses y necesidades diferentes a las nuestras, por lo tanto, un reto para las escuelas es educar en derechos humanos y convivencia. Desde ahí, convivir significa encontrarse y conversar, compartir vivencias y construir espacios armoniosos, participar y cooperar partiendo de la diversidad y el pluralismo, desde ahí la educación en derechos humanos hace significativos aportes al proceso educativo y a la convivencia en los centros escolares (Rodino, 2012).

Otros factores relacionados con los problemas conductuales como indican Reichle y Wacker (1993) son el desempleo masivo en zonas rurales que produce cambios a nivel escolar, rendimiento y comportamiento en los niños; que las escuelas dan poca respuesta a la crisis comunitaria; y que existen aspectos problemáticos en el acercamiento ideológico al tratamiento de los trastornos de conducta e intrusismo de medicación psicoactiva (Kemp, 1996).

\section{El aprendizaje cooperativo}

El aprendizaje cooperativo es el empleo didáctico de grupos reducidos en los que los alumnos/as trabajan juntos para maximizar su propio aprendizaje y el de los demás. La cooperación consiste en trabajar juntos para alcanzar objetivos comunes. Los grupos formales de aprendizaje cooperativo garantizan la participación activa del alumnado en las tareas intelectuales de organizar el material, explicarlo, resumirlo e integrarlo a las estructuras conceptuales existentes. El objetivo grupal de maximizar el aprendizaje de todos los miembros motiva a los estudiantes a esforzarse y a obtener resultados que superan la capacidad individual de cada uno de ellos.

Basándonos en la reflexión de que si existen menos conflictos, aprenderemos más, instauramos medidas que nos orienten hacia el éxito académico de los estudiantes, conservando la máxima exigencia y calidad de la enseñanza. Por ello, decidimos emplear una técnica de animación y creación audiovisual para favorecer la participación del grupo-clase y la inclusión a través de una metodología colaborativa.

\section{La competencia digital}

Las competencias básicas se incorporan a la legislación educativa española en el año 2006 con la aparición de la Ley Orgánica 2/2006, de Educación. Esta sistematiza las competencias básicas en ocho, siguiendo las recomendaciones del Parlamento Europeo, entre las que se incluye la referida al «Tratamiento de la información y competencia digital». Esta competencia supone pues un reconocimiento curricular. En la
LOMCE (2013) siguen siendo elemento esencial curricular con el nombre de "competencias clave" entre las que se incluye: comunicación lingüística, matemático-científica-tecnológica, digital, aprender a aprender, iniciativa-espíritu emprendedor, socialescívicas y conciencia-expresiones culturales.

Compartimos con Levis (2006, p. 79) que las TIC no deben ser un fin en si mismas, es imprescindible darles un uso significativo que no solo sea capaz de superar los prejuicios que dificultan su incorporación en la educación, sino que permita que sean utilizadas para formar en el sentido amplio del término en el que, sin olvidar el cómo se hace, tenga prioridad el para qué se hace, dentro de un proyecto pedagógico integral diseñado en función de las necesidades de docentes y alumnos y de la sociedad de la que son parte.

Como señalan Pérez y Delgado (2012) históricamente la competencia digital y la competencia audiovisual han permanecido claramente separadas. Mientras la competencia audiovisual se centraba en los conocimientos, habilidades y actitudes relacionadas con los medios de comunicación de masas y el lenguaje audiovisual, la competencia digital abordaba la capacidad de búsqueda, procesamiento, comunicación, creación y difusión por medio de las tecnologías.

Masterman (1993: 275-284) sienta las bases de lo que se ha considerado la base de la educación en medios, haciendo hincapié en la alfabetización audiovisual y la colaboración entre familia, profesorado y profesionales de los medios de comunicación, así como en la adecuada formación de los docentes y la creación de instituciones que fomenten la interacción y la integración de la educación mediática en las aulas.

Según Balanskat et al (2006) el uso de las TIC influye positivamente en el rendimiento educativo en las escuelas de Educación Primaria, mejora los niveles y resultados de los escolares, y las escuelas con mayores niveles de madurez en tecnologías demuestran un aumento más rápido en las puntuaciones de rendimiento que aquellos con niveles más bajos.

Todos estos procesos de mejora van encaminados hacia el logro de un sistema de calidad y para conseguirlo es fundamental llevar a cabo un proceso evaluativo. Para ello es necesario entender la evaluación como "un proceso contextualizado y sistemático, diseñado intencional y técnicamente, de recogida de información relevante, fiable y válida, para emitir juicios valorativos en función de unos criterios preestablecidos y tomar decisiones” (Fernández-Díaz, 2002: 28).

\section{El stop-motion como herramienta tecnológica}

El stop-motion es una de las técnicas de animación más antiguas y más utilizadas en la industria del cine, los videoclips y la televisión. El uso de esta requiere siempre de una cámara de vídeo, de cine o de fotografía. Con tener un poco de creatividad, una cámara de fotos y una gran dosis de paciencia, podemos producir un vídeo con esta técnica artesanal ya que no es necesaria ni una gran inversión económica en equipamiento ni ser un experto en edición de vídeo. 
Consiste en tomar fotografías de un objeto, haciendo cambios sutiles en su posición o en la forma del mismo, para que al reproducirse todas las imágenes como una serie continua, se obtenga la ilusión de movimiento. Es una animación en estado puro, ya que se genera el movimiento del producto de forma manual.

Se utiliza la grabación "fotograma a fotograma" o "cuadro a cuadro" (frame a frame) Es un proceso que generalmente se debe realizar en un espacio cerrado en el que nada se debe mover a no ser que el animador lo desee incluyendo las cámaras, luces y escenografía. Como recurso educativo ofrece múltiples posibilidades con las que hacer más motivador y completo el aprendizaje.

\section{Objetivos}

Pretendemos dar a conocer las posibilidades de una herramienta didáctico-pedagógica útil para el docente y motivadora para el alumnado, que promueva el cambio de hábitos disruptivos de los estudiantes hacia habilidades sociales cooperativas y de participación a través de la mejora de la competencia digital.

Objetivo general. Producir un cortometraje en un grupo-clase con problemas de convivencia.

Objetivos específicos. Comprender y producir textos para aprender y para informarse. Conocer y hacer uso de estrategias y normas para el intercambio comunicativo. Determinar los problemas que puedan tener algunos estudiantes para trabajar juntos, e intervenir para aumentar la eficacia de los grupos de aprendizaje. Participar activa y cooperativamente en interacciones espontáneas propias de la vida cotidiana y de la actividad de aula, y en otras más formales y dirigidas. Hacer uso de los conocimientos de la lengua para hablar y escribir adecuadamente. Emplear documentos video-gráficos y sonoros como medio de obtener, seleccionar y relacionar, con progresiva autonomía, informaciones relevantes para ampliar los aprendizajes utilizando técnicas de stop-motion. Usar las posibilidades básicas ofrecidas por programas de texto, imagen y dibujo para crear, manipular y combinar textos e imágenes de manera creativa. Utilizar eficazmente procedimientos de búsqueda, recogida y procesamiento de la información, elaborar y memorizar conceptos. Valorar los medios de comunicación social como instrumento para aprender y acceder a las informaciones y experiencias.

\section{Método}

El estudio de casos constituye un método de investigación para el análisis de la realidad social e implica un proceso de indagación detallado, comprensivo, sistemático y en profundidad del caso o los casos objetos de estudio. En este estudio también se considera el método de investigación-acción, ya que el diseño de la misma se orienta al cambio y está dirigido a la mejora de las condiciones actuales. Con respecto a la investigación-acción Tójar (2006, p. 108) menciona: "No basta con interpretar, hay que actuar".

\section{Participantes}

Este estudio ha sido desarrollado durante el curso académico 2014-2015, en un centro de titularidad pública, en una villa de la provincia de Ourense.

La muestra seleccionada de carácter intencional [consideramos la edad y el curso escolar, así como la pertenencia al grupo-clase de estudiantes con dificultades de aprendizaje] consta de 25 alumnos/as, $(n=25)$ de tercer curso de Educación Primaria, de edad comprendida entre 8 y 9 años. El grupo-clase está formado por 16 niños y 9 niñas, con problemas de convivencia y con varios niveles dentro del aula.

Los estudiantes pertenecen a familias de un contexto socioeconómico y cultural medio-bajo, de estas algunas en situación de riesgo social. Hemos utilizado una estrategia de triangulación de datos para reconocer los elementos que intervienen obteniendo de esta manera un estudio más contextualizado.

El plan tuvo su origen en la gestión de la convivencia, después de detectar la necesidad de establecer pautas de mejora para la convivencia y resolución pacífica de conflictos en el grupo-clase objeto de estudio.

Dentro de los proyectos trimestrales que venimos desarrollando desde la tutoría en el centro escolar, centrado en el desarrollo de las Competencias Básicas, el trabajo cooperativo y la integración de las TIC, se vio la posibilidad de estudiar la asignatura de Lengua Gallega desde las Nuevas Tecnologías. Para ello realizamos una serie de tareas interdisciplinares que dieron como resultado la comprensión de los contenidos curriculares.

El Programa de Intervención Cooperativo consta de 20 sesiones, que se han llevado a la práctica a lo largo de los meses de febrero, marzo y abril de 2015. El horario estipulado para su implementación ha sido temporalizado (lunes, miércoles y viernes) en la sesión de Lengua Gallega, con una duración de 90 minutos, después del Recreo. Su actuación está justificada en el Plan para la Mejora de la Convivencia del centro educativo. La perspectiva inclusiva está presente en todo el proyecto.

Para el desarrollo de la experiencia, se organizó el aula con criterios de agrupamiento heterogéneo, contando con el trabajo conjunto de dos docentes en la misma. En el ámbito del aprendizaje las actuaciones que se han llevado a cabo tienen que ver con iniciativas de tipo organizativo y metodológico, así como con la utilización de materiales innovadores

\section{Instrumentos de recogida de información}

- La observación participante.

- La observación estructurada de la práctica de los docentes.

- La técnica sociométrica del Sociograma.

- Las interacciones colaborativas.

Instrumentos de evaluación. En el desarrollo de este proyecto se han combinado diversos métodos y técnicas de investigación cualitativas, como entrevistas y grupos de discusión, revisión documental y también, 
técnicas cuantitativas, como la consulta realizada a diferentes agentes de la comunidad educativa través de un cuestionario de valoración.

\section{Procedimiento}

El proceso del estudio comienza con un diagnóstico inicial en el que se valoran las necesidades comunes y se identifican las principales dificultades $\mathrm{u}$ obstáculos, utilizando principalmente las técnicas dialécticas e interpretativas. Se continúa con la elaboración de un plan de acción preliminar donde se establecen las prioridades iniciales y se toman las primeras decisiones para el cambio.

El programa se lleva a la práctica a partir de las actividades de las diferentes sesiones que tratan de transformar la situación actual de la conflictividad del grupo-clase, al mismo tiempo que se trabaja simultáneamente en la organización, categorización y sistematización de la información que se obtiene a través del software para análisis cualitativo Atlas.Ti.

Posteriormente en la fase de resultados se analizan y sintetizan las informaciones del centro educativo valorando y reconsiderando la propuesta para tener un nuevo análisis de la prevención en el centro.

Diseño e Implementación del Cortometraje. Después de haber recibido una información básica sobre el lenguaje audiovisual, el plan de trabajo con este recurso comienza con el alumnado a partir de un braing-storming (tormenta de ideas) Posteriormente se les plantea la necesidad de realizar un guión previo y un story-board (viñetas que narran el guión) para comenzar a trabajar en el aula, individualmente para ejercicios concretos y en equipos de cinco en los que tienen que especificar las funciones que van a ejercer.

Nos han servido cámaras digitales de fotografía sencillas y dispositivos móviles para capturar imágenes, teléfonos con cámara, cámaras web, etc. que sujetamos en un trípode.

Las cartulinas, telas y pinturas, etc. nos sirven para crear escenarios o fondos. Plastilina, foami, tijeras y dibujos para la creación y manipulación de los personajes.

En el aula se instalan aplicaciones informáticas de software libre que nos permiten un periodo de prueba. Todos los materiales y recursos han sido compartidos. En una primera sesión y como actividad de introducción-motivación, se le muestran ejemplos de proyectos realizados con la técnica stop-motion, para comprender sobre todo las diferencias, en lo que a técnica se refiere, con proyectos de tipo time-lapse o slow-motion.

En una segunda sesión, realizamos un pequeño stopmotion «artesano» con tres sencillos elementos: una casa de muñecas, un juguete y una aplicación móvil. En menos de 10 minutos podemos tener el proyecto terminado. Con una fotografía cada 5 segundos y un total de 100 disparos que realiza el dispositivo móvil de forma automática, es suficiente para que la aplicación móvil monte el proyecto final y obtenga un resultado similar al de un vídeo casero. Un sencillo stop-motion puede servir para hacerse una idea de qué cambios son necesarios en cada fotograma para obtener el efecto de movimiento deseado.

De este stop-motion, merece verse también el making of donde podemos descubrir parte del proceso detrás de las cámaras. Se toma una fotografía de un muñeco u objeto, luego se mueve el objeto un poco y se toma otra foto. Luego se vuelve a mover y se toma otra foto. Repitiendo este proceso cientos de veces y mostrando las fotografías individuales en secuencia, ¡se crea la ilusión de que el muñeco u objeto se mueve por si mismo y toma vida!

\section{Resultados}

Las familias opinan que participar en un proyecto de estas características les permite comprender mejor a los docentes, valorar más la institución educativa y ser conscientes de las necesidades de sus hijos/as. Un porcentaje elevado de estas han participado en las actividades de difusión del proyecto, lo cual valoran muy positivamente.

Los estudiantes afirman que les aporta una gran motivación, novedad y que el trabajo en equipos colaborativos les ayuda a conocerse mejor.

Los docentes consideran que los logros concretos del proyecto podrían analizarse en relación a los aspectos de convivencia y en referencia a los resultados en el aprendizaje de los estudiantes. Respecto a lo primero tanto docentes como equipo directivo lo señalan como el logro más importante. La convivencia en el centro ha mejorado debido a que existen más formas de resolver los conflictos. Los resultados académicos se han visto, sin duda, afectados por el modelo de gestión de la convivencia.

“... Los chicos/as están más motivados, se distraen menos. Hacen más actividades sin darse cuenta y por lo tanto sin protestar... La disrupción es mucho menor, aunque en los grupos se habla mucho.”(Tutora)

Se constata que dentro de un modelo de gestión participativa de la convivencia, donde se otorga protagonismo a los estudiantes, necesita mejorarse la estructura especializada en el tratamiento de la convivencia en los centros. Esta estructura utilizará como herramienta fundamental el diálogo debido a su gran potencialidad para tratar los conflictos en profundidad.

En consecuencia creen que esto es solo el punto de partida, “... Si hay algo que caracteriza este proyecto es que se trata de un proyecto de investigación, reflexión y acción. Estamos en continua reflexión y debate..." (Docente)

Asimismo consideran que en un principio les ha costado transmitir la intencionalidad de la experiencia a la comunidad educativa. “...La principal dificultad es la transmisión, cómo hacer que todos los sectores implicados sepan lo que se está haciendo y no crean que estamos perdiendo el tiempo, al principio ha sido difícil. "(Equipo Directivo)

Los profesionales que desarrollan el proyecto en el centro coinciden en señalar que no existe un reconocimiento del trabajo realizado, y aunque son felicitados, la propia administración no impulsa ni 
incentiva que los proyectos se consoliden. Algunos logros del proyecto tienen que ver con indicadores como: disminución de sanciones, ausencia de expedientes disciplinarios, existencia de más formas de resolver los conflictos, amplia participación de los estudiantes, existencia de un interés manifiesto entre los miembros de la comunidad educativa.

\section{Conclusiones}

Si la metodología se adecua a las diversas situaciones de aprendizaje, puede ejercer un fuerte impulso de integración del alumnado en el centro educativo.

El control del tiempo en cada uno de los grupos colaborativos, para realizar las actividades asignadas, resulta muy motivador para el alumnado e intensifica su ritmo de trabajo.

Una idea que parece estar presente en relación con la educación de los estudiantes es el trabajar por valores como la imparcialidad y el éxito para todos, y en ese sentido el enfoque de inclusión está presente en todo el proyecto.

En el ámbito del aprendizaje las actuaciones llevadas a cabo tienen que ver con decisiones de tipo organizativo y metodológico, así como con el uso de materiales innovadores que incrementen este enfoque inclusivo. El mayor esfuerzo se ha dedicado a la mejora de medidas ordinarias de atención a la diversidad, destinadas a todo el alumnado. Implementar el aprendizaje cooperativo en el grupo-clase exige esfuerzo y disciplina.

La participación de los estudiantes en la gestión de la convivencia es un elemento en la mejora del clima del centro educativo, pero debe ser una colaboración mantenida por los docentes y con un método de funcionamiento que permita incorporarla a la dinámica habitual del centro educativo.

El uso de la técnica stop-motion como herramienta didáctico-pedagógica en la Educación Primaria para la mejora de la convivencia, vinculada a la práctica real en el aula, posibilita la aplicación de una metodología activa, de aprendizaje por competencias, de innovación y mejora de los procesos y los resultados de los estudiantes.

\section{Referencias Bibliográficas}

Balanskat, A., Blamire, R. y Kefala, S. (2006). The ICT Impact Report. A review of studies of ICT impact on schools in Europe. European Schoolnet, European Comission. http.//ec. europa.eu/education/doc/reports/doc/ictimpact. pdf

Domínguez, J. y Pino, M. (2007). Las conductas problemáticas en el aula: propuesta de actuación. Revista Complutense de Educación, Vol., 19, Núm. 2, pp. 447-457

Fernández-Díaz, M.J., Álvarez-Fernández, M. y Herrero, E. (2002). La dirección escolar ante los retos del siglo XXI. Madrid: Editorial Síntesis.
Ferrero, C. (2007). Un reto en la escuela: los derechos humanos y la convivencia. Madrid: Editorial Cruz Roja Juventud.

Jares, X. (2001). Educación y conflicto. Guía de educación para la convivencia. Madrid: Popular.

Kemp, F. (1996). The Ideology of Aversive Treatment as Applied to Clients and Colleagues. Child and Family Behavior Therapy, 18(1) 9-28.

Levis, D. (2006). Alfabetos y saberes: la alfabetización digital, Comunicar, 26, pp 78-82.

Masterman, L. (1993). La enseñanza de los medios de comunicación. Madrid: De la Torre.

Pérez, M.A y Delgado, A. (2012). De la competencia digital y audiovisual a la competencia mediática: dimensiones e indicadores. Comunicar, $\mathrm{n}^{\circ} 39$ v. XX.

Reichle, J. y Wacker, D. P. (eds.) (1993). Comunicative Alternatives to Challenging Behavior: Integrating Functional Assesment and Intervention Strategies (vol. 3). BaltimoreMaryland: Brookes Publishing Co.

Rodino, A.M. (2012). Programa Interamericano sobre Educación en Valores y prácticas democráticas (Serie sobre educación y democracia, Vol. 2). Washington, D.C.: Oficina de Educación y Cultura DDHEC/SEDI ONU. Recuperado de http://portal.oas.org/LinkClick.aspx?fileticket= 8Fxs DEfC9fs\% 3D\&tabid=1232

Tójar, J. C. (2006). . Investigación cualitativa. Comprender y actuar. Madrid: La Muralla.

Vega-Hazas, J. (2009). Comunicación entre el colegio y la familia. Madrid: Ediciones Internacionales Universitarias. 